\title{
Research on Micro-blog Marketing Mode of Domestic Films —-Take "Pass Through Your World" as an example
}

\author{
Xiaowen Zhou ${ }^{1}$, a \\ ${ }^{1}$ School of Management, Yulin University, China,719000 \\ a2393219363@qq.com
}

Keywords: Domestic Film; Micro-Blog Marketing; Strategy

\begin{abstract}
Based on the theory of micro-blog marketing, in the movie "passing from your world "as the study object, based on the movie "passing from your world " micro-blog marketing application specific analysis, find out the success of micro-blog in the marketing aspect, and summarizes the successful experience of other domestic. The movie has enlightenment in the micro-blog marketing application.
\end{abstract}

\section{Introduction}

The movie passing from your world is part of the original name. According to the story, the original novel first name of "bedtime story" on the Internet was crazy forwarded by the good movie shoot fresh art film director Zhang Yibai and author Zhang Jiajia known as healing together to create, build Deng Chao, Bai Baihe, Yang Yang and other actors from the movie. Your world pass $>$ in September 29th national release, released the first day at the box office reached 72 million 440 thousand, second days at 12 noon break billion total box office success, the first national archives released two weeks off, the cumulative box office of 650 million yuan. The film at the box office success is mainly due to marketing practices to create new styles, for example micro-blog propaganda micro-blog to search, the number of passing from your world "as the keyword super 4 million 980 thousand, micro-blog official movie fans have exceeded 1 million 100 thousand. Many fans said, himself in the cinema This movie is affected by Sina. Micro-blog's overall "passing from your world > micro-blog marketing is the main way of precision marketing, marketing, marketing activities, celebrity marketing, emotional marketing and content marketing.

\section{The Micro-Blog Marketing Mode of "Pass Through Your World"}

Precise Positioning Marketing. Micro-blog has a strong pertinence, pay attention to the movie passing from your world. Fans of the film's customers or potential consumers, the official film of precision marketing, micro-blog users can use micro-blog keyword search, find out all about the film. The original book < the world from your past > first madness is spread on the Internet, so it is the love of young people, therefore accumulated a certain amount of fans. The official movie in the audience after accurate positioning, to fully understand the social habits of these fans forum, entertainment consumption concept, for they develop precise marketing fans. There are young people as the current mainstream consumers movie. They are fashionable and advanced the concept of the pursuit of fashion, watching movies has become a way of entertainment, so choose the movie marketing tools are mostly related with young people, such as micro-blog, opal, watercress, Video website and social media, the media are the main users of some young people. At the same time, some of the characters in the film set itself and they have the same place, put these related content to micro-blog, the dissemination and promotion effect is very good. The movie from your world through "in the eleven National Day golden week period many movie become a dark horse at the box office, the talent shows itself, precision marketing contributed.

Micro-Blog Topic Marketing. In the movie shooting on the eve of Mesozoic because actor Deng Chao, little meat Yang Yang, Princess Zhang Tianai et al to join caused a discussion of micro-blog users is fierce, broke every message of the movie have caused netizens attention, 
netizens spontaneously in micro-blog launched related topics, the movie is not keywords release, "the whole world has passed" from the line of each dimension into the public eye. In the interaction between the film starring funny is a big topic, the film will make full use of each actor brought to star topic, and make the film hook, thereby expanding the visibility of the film, so focus the public no surprise fall in the movie.

Micro-Blog Interactive Marketing. In the movie after the release, the producers have a series of interactive activities with the fans. The film officially launched in micro-blog, mobilize the fans around the world to share their friends in micro-blog's viewing experience, spiritual growth, emotional story, let each viewer can participate in this movie, feel this movie is closely related with their administrative micro-blog in the film. At the same time, micro-blog also launched a series of activities such as lottery ticket, starring with topic of online ticketing, with the topic of "taking photos at hand in the world" Sun stub yourmovie review draw, carry out "passing your reader" and other activities. There are official movie NetEase and cloud music, litchi FM, Penguin FM and other Internet Radio jointly launched the official radio station of this activity, micro-blog and frequent interaction, publicity program "all over the world to listen. In this activity, the official radio station by inviting guests to show Xuan star After the transfer campaign, the audience can interact in a similar way into radio hotline telephone and star chat or on demand songs, finally star guests by reading the original novel story fragments as bedtime stories in each of the programs. The end of each program and the official movie was invited guests of micro-blog will forward interactive publicity, at the same time the network radio the official micro-blog and the client and APP into the home page, column area, area and other major publicity also highlight the show. In short, the official launch of the film are greatly to the interactive activities of film publicity.

Celebrity Effect Marketing. First of all, film producers in micro-blog released MV movie songs for the film publicity preheating, Chinese music after the character of Faye Wong and singer songwriter Li Ronghao for the film the singing of the news caused the attention of Internet users, the seven stars of the film is the currently popular actor, they themselves have extremely loyal fans and a strong audience. Starring Deng Chao is one of the most bankable actress actor, he is also the permanent guest a variety of running man, for his role in the drama version of "meat Yang Yang smiled very little in the Xiao Nai corner into God for all fans sister God, director Zhang Yibai has directed drama film two version of love in the end is known, so they are in micro-blog in every word and action will cause fans, forwarding and comments. So the film star, director and producer of the film related text, pictures, video. Micro-blog this platform release, after fans of comments and forwarding micro-blog apart in a viral propagation velocity spread quickly, the micro-blog send hot let more friends to see micro-blog, makes the film as easy as blowing off dust to get attention, good effect of film publicity.

Story Emotion Marketing. The movie as a bedtime healing story, the protagonist of "little people" in the movie set is very popular at heart, the audience can find themselves or the people around in the shadow of the protagonists by mapping these little people, seven stars, seven lives, seven lives, in the film about family, friendship, love and life's passing is easy to empathize. Such as the Chen Mo family and the risk of dementia between grandma and two brothers, the brothers, and the cruel reality of the swallow between PigHead and love. So one of the film's official propaganda way is emotional marketing, whether it is in the film the release before or during the exhibition, the movie's official micro-blog will send some moving pictures and video on micro-blog, or some connection with the audience, the audience friends incentive text. Chicken soup.

\section{The Success of Micro-Blog Marketing}

Precision of Consumer Groups. We all know that micro-blog is a major feature of the user can find micro-blog search keywords, blogger, users love or interest therefore, micro-blog marketing content to cater to the target group's concerns, the only way to arouse the interest of the audience, so in the movie marketing in the whole link accurate positioning of the audience it is necessary to something from your main reading world pass the original novel is "young man, the seven starring movie is the choice of the fans extremely popular artists and fans of these young actor's main 
strength is mainly concentrated in a certain economic capacity of 80 after 90 , clearly the consumer positioning it so the film at the beginning of the creation. In addition, the audience is watching this movie is the first movie trailer, starring the director, information, posters and the big theme song MV The influence factors. Therefore, in its official micro-blog operation, to the main content of these aspects, and the movie passing from your world > official micro-blog will from time to time to release some actors behind the scenes in the novel, the classic lines, attract the audience to the cinema viewing. From the above we can see that movie. The official for the positioning of their target audience of film accurately.

Celebrity Effect Maximization. In the film before, through the expansion of movie star publicity is the most effective way to the attention of young people now have star worship, these stars have a strong fanbase, stars in the micro-blog fans will be every word and action, comments forwarded. In addition the star forwarding and interaction will forward and interaction driven by their fans groups, making micro-blog content transmission range is wider, and the interactive behavior will be forwarded between the star and the target audience formed a strong public opinion field and exchange. There are stars of opinion leaders force and its image characteristics will affect the choice of viewing audience. Before the movie from your world pass > release, seven starring Deng Chao, the film Yang Yang, Yue Yunpeng and other related information continue to release the film, and interact with the star friends, which led to fans of the film in the forward Into the hot topic of micro-blog. There are days before the release of Faye Wong singing of the song "you wait for me in the end point $>\mathrm{MV}$ after the broadcast is caused by forwarding. In addition the movie stars of the film audience after mixed reviews, these evaluations mainly concentrated in different movie and novel narrative style, and the acting.

Specialization of Marketing Model. A good movie can lead the people to interact in micro-blog, the first is to create innovative topics, and to implement interaction with the audience. The movie passing from your world on the official Sina micro-blog in 2016 at the start of May 5th update, micro-blog recorded most of the content related news film, such as shooting in the actor between various interactive scenes, or some other actors, interaction with the fans, or a "passing from your world on some classic quotations. After filming completed into the release period, movie posters, Pilot Trailer in the first time micro-blog released. The marketing team through a variety of activities, but also makes the film not released, the keyword" world pass "from the line of each angle into the public eye. In addition, after the release of the film, the film side by forwarding a high heat in the micro-blog, released the movie theme Song, brand sponsorship, micro-blog interactive live roadshow, offline advertising and other activities, multi-faceted publicity, as people mobilize the participation possible. We can see the movie passing from your world on the entire marketing mode is like a nine chain, chain, from production to promotion to release. The marketing team, comprehensive tracking, continuous manufacturing topics to interact with friends, it can be seen that this is a full range of movie Xuanfa, also can see the marketing team of professional, skilled marketing mode, the film finally made 814 million at the box office good result cannot do without the marketing team effort.

\section{The Revelation of Movie Micro-Blog Marketing of "Pass Through Your World"}

Marketing Test + Emotional Marketing. In the propaganda film not only to refine the market, accurate positioning of movie audiences, but also playing the emotional card. Because the film is not only a commodity, but also a cultural spirit, so in the audience positioning, also need to introduce emotional marketing, in order to ensure the smooth development of micro-blog film marketing. Because the film features of micro-blog's own marketing provides a good natural and market segments, the movie is in order to allow the public to enjoy, let the audience see, so both the film producers, or issuers need to change the marketing concept. To establish audience oriented film marketing consciousness, the center point of the audience as the movie marketing, clear the preferences of the audience demand from the angle of audience demand, then positioning propaganda films, promote the film marketing by the seller's market to buyer's market changes. 
How to let the public see and willing to enter the cinema Look, we need to vigorously promote the film marketing. While the film release party of their own movie audience, according to the needs of the audience, to carry out a series of promotional activities, so micro-blog users can according to their own preferences, and then through the micro-blog keyword search, find out all about the movie, and the film side interaction, make the film gradually popular. And more importantly, the movie publicity in the promotional video, to know the hearts of the audience, the focus of the audience, and find the resonance point of the audience, and then adding the appropriate emotional marketing, the most willing to let the audience into the cinema.

Make Good Use of Celebrities. With the rapid development of network culture era, fans economy is becoming more and more popular, with millions of fans of the network celebrities have enormous influence and appeal. In micro-blog this public forum, celebrities will express views and fans of their friendly interaction with the open platform, thereby narrowing the idol and fans of the distance. A point worth mentioning is that micro-blog has two-way interaction and mining characteristics of potential consumers, so the star in his movie propaganda or company's movie, will get a rapid diffusion of so many potential audience to accept its communication with advertising component news on the micro-blog platform, and to promote their consumer behavior. So more pay attention to the existence of extensive micro-blog opinion leaders, celebrities and active users, and they have a lot of fans and attention, so they will cause every word and action Big publicity and promotion role. Therefore, the opinion leader, star and other micro-blog content and film marketing butt up, and actively use their popularity in micro-blog, will bring good micro-blog marketing effect

Pay Attention to Content Marketing. In the media environment, everyone can participate, the micro-blog marketing content of the higher quality requirements, not only to meet the diversified tastes, but also to seize the common people's heart, something that resonates, because only the marketing content itself, will attract the public's attention compared to the overwhelming. The release and water flow, the audience is more willing to see the good content of innovation and extension, or have more marketing channels, with more $\mathrm{V}$ forwarding support and a good movie schedule, or will be broken. Therefore making cards and issued to the box office to obtain good results, we must uphold the principle of the content for the principle, so in the micro-blog marketing to make micro-blog creative content, but not from the film itself, closely around expressed the theme of the film, and then to sell the film.

Building Professional Marketing Team. A professional team is required in any industry, especially in the marketing industry, so the movie marketing also need professional marketing talents. Micro-blog as a great flow of public forum, it provides a good marketing platform for film marketing, but the application of micro-blog marketing is not particularly mature, lack of micro-blog marketing personnel, and will be able to reach a perfect combination of film and micro-blog marketing talent is scarce. So the formation of a professional knowledge of micro-blog marketing personnel is very necessary.

\section{References}

[1] Liu Suyao. New media era movie - micro-blog marketing cases of [J]. new media research, with "Mermaid" 2016, (16):87-88.

[2] Li Xuemei. Discussion on the micro-blog marketing [J]. modern economic information, 2014, (4): 349.

[3] Fan Yuming micro-blog - the movie marketing new [J]. film review, 2012, (10): 66-67.

[4] Zhu Yandan, Jing Ming. Entertainment V communication behavior and the influence of [J]. news fans, 2015, (6): 58-62.

[5] Li Linlin, Liu Cheng Xue. Analysis of the [J]. era, the 2015 film micro-blog marketing strategy under the new media era, (9): 66-67 